Original Research Paper

\title{
Peran Media Informasi sebagai Sarana Penunjang Wisata Kolam Manggong Desa Batu Kumbung
}

\author{
Muhammad Cahyadin $^{1 *}$, Santi Ladiansari², Hibatunnur ${ }^{3}$, Asmarita $^{2}$, Oky Maya Selhari ${ }^{3}$, Cathur Septian \\ Raharjo $^{4}$, Wahyu Fitriani ${ }^{4}$, Nurfadillah Armita ${ }^{2}$, Arya Saqi Bimantara ${ }^{1}$, Fajrin Saputra ${ }^{4}$, Nuriadi ${ }^{5}$ \\ ${ }^{1}$ Program Studi Kehutanan, Fakultas Pertanian, Universitas Mataram, Indonesia \\ ${ }^{2}$ Program Studi Agribisnis, Fakultas Pertanian, Universitas Mataram, Indonesia \\ ${ }^{3}$ Program Studi Agroekoteknologi, Fakultas Pertanian, Universitas Mataram, Indonesia \\ ${ }^{4}$ Program Studi Ilmu Hukum, Fakultas Hukum, Universitas Mataram, Indonesia \\ ${ }^{5}$ Program Studi Bahasa Inggris, Fakultas Keguruan dan Ilmu Pendidikan, Universitas Mataram, Indonesia
}

https://doi.org/10.29303/jpmpi.v3i2.633

Sitasi: Cahyadin, M., Ladiansari, S., Hibatunnur., Asmarita, Selhari. O. M., Raharjo, C. S., Fitriani, W., Nurfadillah, A., Bimantara, A. S., Saputra, F., \& Nuriadi. (2021). Peran Media Informasi sebagai Sarana Penunjang Wisata Kolam Manggong Desa Batu Kumbung. Jurnal Pengabdian Magister Pendidikan IPA, 4(1)

\author{
Article history \\ Received: 05 Januari 2021 \\ Revised: 19 Februari 2020 \\ Accepted: 05 Maret 2021 \\ *Corresponding Author: \\ Muhammad Cahyadin, \\ Program Studi Kehutanan, \\ Fakultas Pertanian, Universitas \\ Mataram, Indonesia; \\ Email: cahyadinm@gmail.com
}

\begin{abstract}
Desa Batu Kumbung merupakan salah satu Desa dari 10 Desa yang berada di Kecamatan Lingsar Kabupaten Lombok Barat. Desa ini terdiri dari 8 Dusun, salah satunya Dusun Manggong yang memiliki potensi berupa mata air yang dijadikan kolam renang dan menjadi pusat wisata desa Batu Kumbung, yakni wisata air kolam manggong. Berbeda dengan kebanyakan kolam renang lainnya, air kolam manggong bersumber dari mata air alami yang akan membuat pengunjung merasakan sensasi dingin dan segar ketika berendam. Meski demikian, kolam renang ini masih kurang dikenal oleh masyarakat yang berasal dari luar Desa dikarenakan kurangnya informasi dan promosi mengenai tempat wisata ini sehingga diperlukan media informasi dan promosi. Program ini menggunakan metode kualitatif deskriptif, Adapun hasil yang didapatkan dari program ini berupa adanya media informasi di kawasan wisata kolam renang Manggong desa Batu Kumbung kecamatan Lingsar yang dapat dilihat oleh wisatawan.
\end{abstract}

Keywords: Desa Wisata; Media; Informasi; Desa Batu Kumbung.

\section{Pendahuluan}

Sektor pariwisata sangat penting bagi perekonomian Indonesia. Dalam beberapa tahun terakhir, kontribusi sektor pariwisata terhadap ekonomi Nasional meningkat secara signifikan. Hal ini dapat dilihat dari kontribusi sektor pariwisata terhadap total ekspor barang dan jasa yang

meningkat tajam dari $10 \%$ pada tahun 2005 menjadi $17 \%$ pada tahun 2012. Sektor pariwisata memberikan kontribusi langsung terhadap Produk Domestik Bruto (PDB) sebesar $4,80 \%$ pada tahun 2019. Nilai tersebut meningkat $0,30 \%$ dibandingkan tahun lalu. Peningkatan kontribusi ke
PDB di dorong oleh meningkatnya jumlah wisatawan Mancanegara, Nusantara dan Investasi (KEMENPAR, 2019).

Pariwisata memiliki peran yang besar dalam pembangunan Nasional. Karena, selain menghasilkan pendapatan dan sekaligus sebagai penghasil devisa, sektor pariwisata berkaitan erat dengan penanaman modal asing. Turis-turis yang datang ke Indonesia adalah termasuk mereka yang berhubungan bisnis

Jurnal Pengabdian Magister Pendidikan IPA dengan Indonesia. Sehingga pemerintah terus berupaya untuk melakukan pengembangan sektorsektor wisata yang ada di Indonesia, termasuk yang berada di Pulau Lombok. Lombok merupakan 
sebuah pulau yang terletak di kepulauan sunda kecil atau Nusa Tenggara yang terpisahkan oleh Selat Lombok dari Bali di sebelah barat dan Selat Alas di sebelah timur dari Sumbawa. Saat ini, Pulau Lombok merupakan destinasi wisata yang terus dikembangkan oleh pemerintah Indonesia. Di bidang pariwisata, Lombok memiliki sumber daya alam sangat melimpah begitu juga dengan sumber daya manusia berupa adat istiadat dan budaya, menjadi daya tarik tersendiri yang mampu menarik minat kunjungan wisatawan. Berdasarkan Data Statistik Badan Pusat Statistik Provinsi Nusa Tenggara Barat di tahun 2011 sampai 2015, ratarata setiap tahunnya telah terjadi peningkatan jumlah kunjungan wisata sebesar $8,75 \%$. Sementara itu jumlah kunjungan wisatawan ke Provinsi Nusa Tenggara Barat di tahun 2016 berjumlah 3.094.437 jiwa.

Desa Batu Kumbung merupakan salah satu Desa dari 10 Desa yang berada di Kecamatan Lingsar Kabupaten Lombok Barat. Adapun jarak Desa ini dari pusat pemerintahan Kabupaten Lombok Barat yakni sekitar $23 \mathrm{~km}$ dengan jarak tempuh sekitar $1 / 2$ jam perjalanan. Desa batu kumbung berada di daerah yang sangat subur dengan sumber air yang melimpah serta panorama alam yang masih asri menjadikan desa ini sangat berpotensi untuk budidaya hortikultura, perikanan dan pengembangan sektor pariwisata khususnya wisata air.

Desa Batu Kumbung terdiri dari 8 Dusun yang memiliki potensi wisata masing-masing. Salah satunya Dusun Manggong, yang memiliki potensi berupa mata air yang dijadikan kolam renang dan menjadi pusat wisata desa Batu Kumbung, yakni wisata air kolam manggong. Berbeda dengan kebanyakan kolam renang lainnya, air kolam manggong bersumber dari mata air alami yang akan membuat pengunjung merasakan sensasi dingin dan segar ketika berendam. Selain itu, suasana pedesaan yang masih asri dan sejuk akan menambah ketenagan pengunjung ketika berkunjung kesini. Meski demikian, kolam renang ini masih kurang dikenal oleh masyarakat yang berasal dari luar Desa dikarenakan kurangnya informasi dan promosi mengenai tempat wisata ini.

Media informasi sangatlah penting untuk menunjang keberadaan wisata kolam manggong. seperti yang diketahui bahwa, media informasi sangat dibutuhkan untuk mempermudah wisatawan lokal maupun wisatawan mancanegara ketika ingin berkunjung ke tempat ini. Kurangnya informasi dan promosi mengenai keberadaan wisata Kolam Manggong mengakibatkan wisatawan mengalami kesulitan untuk mengakses layanan informasi sehingga dibutuhkan media informasi yang lebih bagus.

\section{Metode}

\section{Waktu dan Tempat}

Program ini dilaksanakan Selama 10 Hari terhitung sejak tanggal 18 Januari hingga 28 Januari 2021 yang bertempat di Dusun Manggong Desa Batu Kumbung Kecamatan Lingsar Kabupaten Lombok Barat, NTB.

\section{Alat dan Bahan}

Alat yang digunakan dalam program ini berupa palu, gergaji, kuas dan linggis. Adapun bahan yang digunkan berupa cat, triplek, paku, kayu, dan banner.

\section{Tahapan Kegiatan}

Tahapan kegiatan dalam program Pembuatan Media Informasi sebagai Sarana Penunjang Wisata Kolam Manggong Desa Batu Kumbung: 1) Survei lokasi penempatan media informasi. 2) Pengumpulan alat dan bahan pembuatan papan penunjuk arah dan papan informasi kolam. 3) Pembuatan dan pemasangan papan informasi kolam.

\section{Metode}

Artikel ini menggunakan metode kualitatif deskriptif. Nana Syaodih Sukmadinata (2011: 73) mengemukakan penelitian deskriptif kualitatif ditujukan untuk mendeskripsikan dan menggambarkan fenomena-fenomena yang ada, baik bersifat alamiah maupun rekayasa manusia, yang lebih memperhatikan mengenai karakteristik, kualitas, dan keterkaitan antar kegiatan. Selain itu, penelitian deskriptif tidak memberikan perlakuan, manipulasi atau pengubahan pada variabel-variabel yang diteliti, melainkan menggambarkan suatu kondisi yang apa adanya. Satu-satunya perlakuan yang diberikan hanyalah penelitian itu sendiri, yang dilakukan melalui observasi, wawancara, dan dokumentasi.

Dasar penelitian kualitatif merupakan konstruktivisme yang berasumsi bahwa kenyataan itu berdimensi jamak, interaktif dan suatu pertukaran pengalaman sosial yang 
diinterpretasikan oleh setiap individu. Peneliti kualitatif percaya bahwa kebenaran ialah dinamis dan dapat ditemukan hanya melalui penelaahan terhadap orang-orang melalui interasinya dengan situasi sosial mereka (Danim, 2002).

\section{Hasil dan Pembahasan}

\section{Kondisi Umum Lokasi}

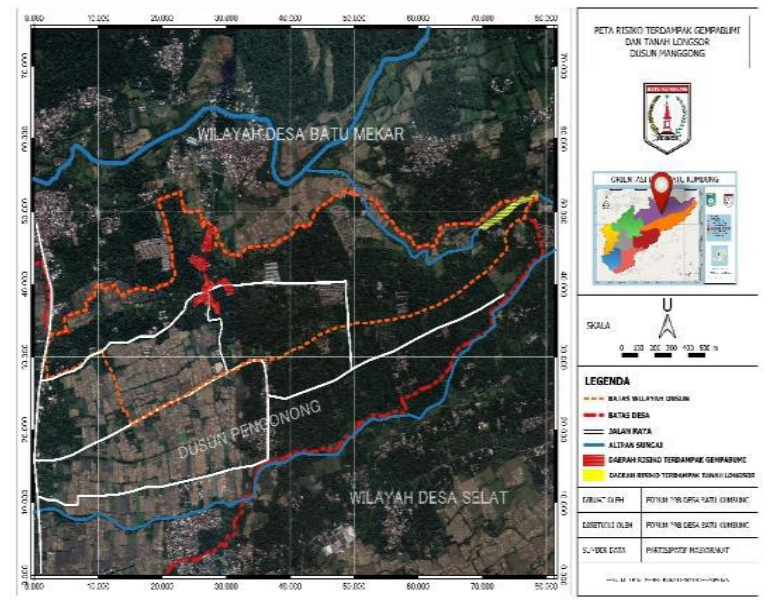

Gambar 1. Peta Dusun Manggong

Dusun manggong terletak di Desa Batu Kumbung Kecamatan Lingsar Kabupaten Lombok Barat. Memiliki jarak tempuh sekitar $23 \mathrm{KM}$ dari pusat pemerintah dengan waktu tempuh $1 / 2$ jam perjalanan. Dusun manggong berada di daerah yang sangat subur dengan sumber air yang melimpah. Kondisi alamnya masih alami dan panorama alamnya yang sangat indah. Dengan kondisi alam seperti ini. Dusun manggong berpotensi untuk budidaya horticultural, perikanan, dan pengembangan sektor pariwisata air.

Dusun manggong teridentifikasi sebagai salah satu dusun yang memiliki potensi wisata dengan luas 156 ha dan menjadi pusat wisata di Desa Batu Kumbung dengan jumlah penduduk sebanyak \pm 941 jiwa. Dengan batas-batas sebelah barat berbatasan dengan wilayah desa Lingsar, di wilayah timur berbatasan dengan desa Suranadi, di wilayah selatan berbatasan dengan desa Selat, dan di wilayah utara berbatasan dengan desa Batu Mekar.

\section{Survei lokasi penempatan media informasi}

Tahapan pertama yang harus dilakukan sebelum penempatan media informasi adalah melakukan diskusi dengan pihak pengelola tempat wisata kolam manggong yakni kepala BUMDES Ijo Tandur yang bertujuan untuk mengetahui media informasi apa saja yang akan dibutuhkan oleh tempat wisata dan sekiranya dapat mendukung keberadaan tempat wisata. Setelah itu, hal yang harus dilakukan adalah menentukan titik-titik lokasi yang strategis untuk menempatkan media informasi yang akan dibuat sehingga diharapkan bisa memudahkan wisatawan untuk menemukan lokasi wisata kolam renang manggong. Dimana, lokasi kolam cukup jauh dari jalan utama sehingga dengan adanya media informasi wisatawan tidak tersesat.

\section{Pengumpulan alat dan bahan pembuatan media informasi}

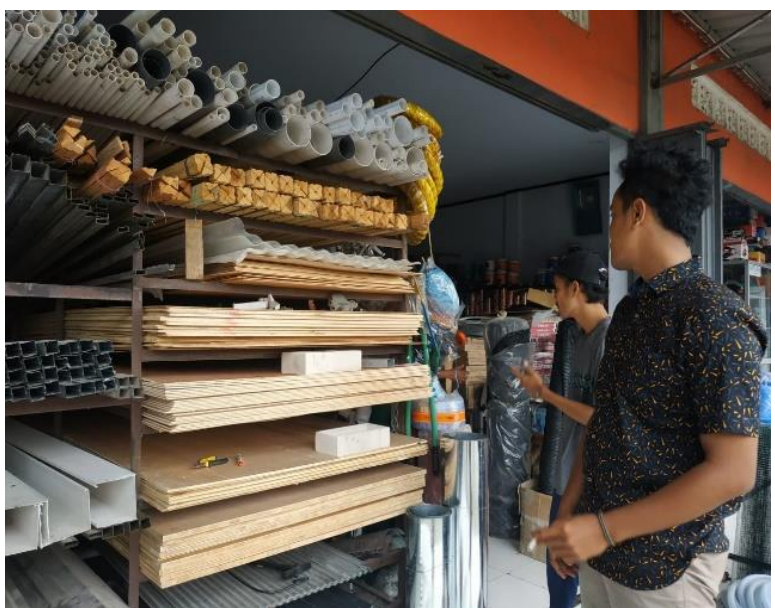

Gambar 2. Pengumpulan bahan pembuatan media informasi

Setelah mengetahui lokasi penempatan media informasi, selanjutnya dilakukan pengumpulan alat serta bahan yang dibutuhkan dalam pembuatan media informasi. Adapun alatalat yang digunakan dalam pembuatan papan penunjuk arah dan papan informasi kolam adalah:

- Palu

Palu atau martil digunakan untuk memberikan tumbukan kepada benda. Palu digunakan untuk memaku dan memperbaiki bentuk media informasi yang akan di buat.

\section{- Gergaji}

Gergaji merupakan perkakas berupa besi tipis bergigi tajam yang digunakan untuk memotong atau membelah kayu, benda dan bahan-bahan yang digunakan untuk membuat papan penunjuk arah dan papan informasi. 


\section{- Kuas}

Kuas digunakan untuk menempelkan cat minyak, akrilik, maupun air pada permukaan kanvas dan pada saat melakukan pewarnaan kayu dan penulisan triplek papan penunjuk arah dan papan informasi kolam sehingga di dapatkan hasil yang lebih rapi.

- Linggis

Linggis merupakan suatu alat yang terbuat dari batang logam yang kedua ujungnya memipih, dengan salah satu melengkung digunakan untuk membuat lubang tanam pada saat menancapkan papan informasi agar lebih kokoh dan tidak mudah rebah sehingga diharapkan dapat bertahan lama.

Adapun bahan-bahan yang disiapkan adalah :

- Paku

Paku adalah logam keras berujung runcing, umumnya terbuat dari baja, yang digunakan untuk memasang kayu, membuat lubang pada kayu, dan melekatkan dua bahan dengan menembus keduanya menggunakan palu atau nail gun yang digerakkan oleh udara bertekanan atau dorongan ledakan kecil.

\section{- Cat}

Cat untuk memberikan ornamen, atau pewarnaan sehingga media informasi yang berupa papan dari bahan triplek dan kayu terkesan lebih hidup dan menarik untuk di baca.

- Triplek

Triplek digunakan untuk meletakkan tulisan aturanaturan maupun informasi yang dibuat untuk diletakkan di sekitar kolam maupun di luar kolam.

- Kayu

Kayu digunakan sebagai penyangga triplek atau papan informasi agar terlihat lebih tinggi dan mudah dibaca oleh wisatawan atau pengunjung.

\section{- Banner}

Berisi informasi berupa tata tertib kolam yang harus dipatuhi oleh pengunjung ketika datang ke kolam manggong sehingga kolam lebih tertib, aman dan nyaman.

\section{Pembuatan dan pemasangan papan informasi kolam.}

Dalam pengembangan potensi wisata kolam manggong, papan informasi sangatlah dibutuhkan. Pembuatan papan informasi dibagi dalam 2 tahap, tahap awal yaitu persiapan (pengukuran kayu, pemotongan kayu, pengecetan kayu), tahap kedua yaitu pemasangan. Pemasangan papan informasi atau plang penunjuk arah kolam manggong di tempatkan dipersimpangan jalan.

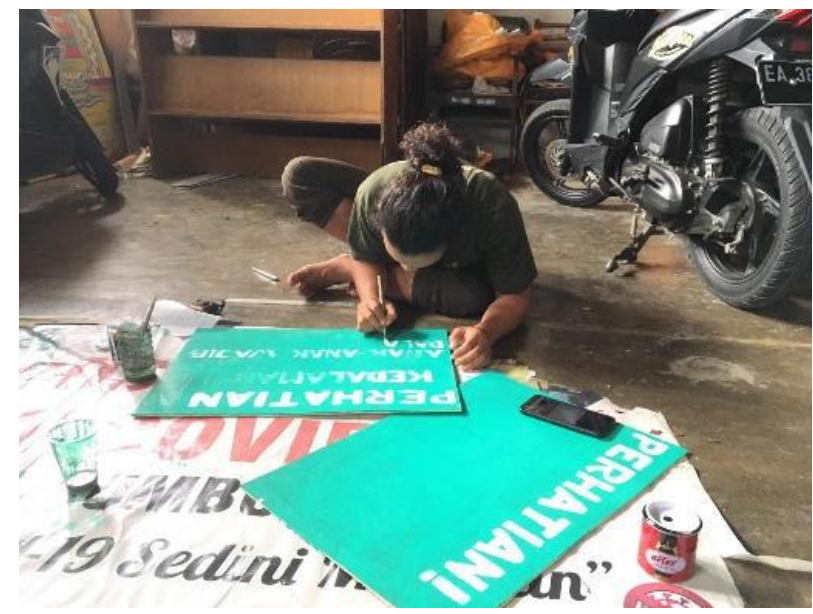

Gambar 3. Pembuatan papan informasi kolam manggong

Maksud dan tujuan pemasangan papan informasi atau plang penunjuk arah untuk memberikan informasi kepada wisatawan sehingga mengetahui keberadaan wisata kolam manggong. Dengan begitu, wisata kolam manggong dapat mengalami peningkatan kunjungan baik kunjungan yang berasal dari Desa Batu Kumbung sendiri maupun yang berasal dari luar desa.

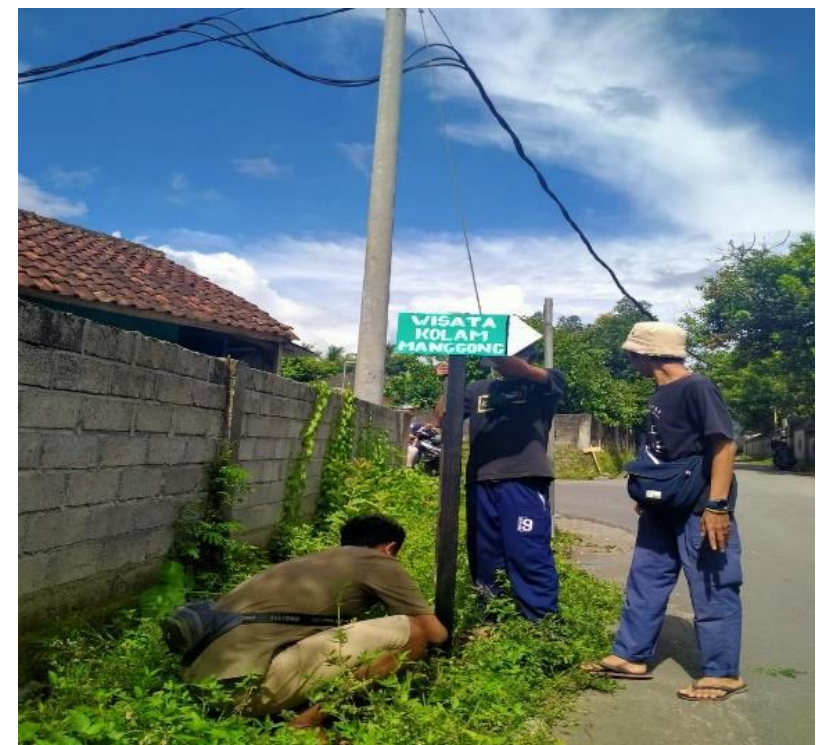

Gambar 4. Pemasangan Papan Penunjuk Arah Menuju Kolam Manggong

\section{Kesimpulan}

Dari berbagai tahapan yang dilakukan pada program Pembuatan papan informasi kolam 
manggong, Dengan adanya pemasangan papan informasi atau plang penunjuk arah diharapkan dapat memberikan informasi yang tepat tentang wisata kepada wisatawan yang ingin berkunjung ketempat wisata sehingga mengetahui keberadaan wisata kolam manggong dan untuk meningkatkan pengunjung yang datang ke kolam renang manggong Desa Batu Kumbung Kecamatan Lingsar Kabupaten Lombok Barat.

\section{Daftar Pustaka}

Sukmadinata, N.S. 2011. Metode Penelitian Pendidikan. Bandung: Remaja Rosadakarya.

Danim, Sudarwan. 2000. Menjadi Peneliti Kualitatif. Bandung: Pustaka Setia 